\title{
The draft of the Regulation (EC) No 852/2004: food safety culture under new administration
}

\author{
Sigune Lopp ${ }^{1}$ (D . Joel M. Goebelbecker ${ }^{2}$. Patrick C. Ruff ${ }^{2}$
}

Received: 26 October 2020 / Revised: 26 October 2020 / Accepted: 13 November 2020 / Published online: 2 January 2021

(c) The Author(s) 2020

\begin{abstract}
The current draft of Regulation (EC) 852/2004 promotes a food safety culture as a general principle. The various stakeholders evaluate this planned new development quite differently. While this is very welcome from a scientific point of view, there are still considerable objections from stakeholders of the area for implementation and monitoring. The challenge is how to integrate the principles into industry, and to measure and verify their effectiveness. In this article, the dimensions of food safety culture are illustrated, and an evaluation system is outlined.
\end{abstract}

Keywords Food safety culture $\cdot$ Regulation (EC) 852/2004 $\cdot$ HACCP $\cdot$ Hygiene

\section{Introduction}

With the publication of the draft revision of Regulation (EC) No 852/2004 on the hygiene of foodstuffs (EC 2020a), the concept of food safety culture is introduced into the legislation as a general principle. Therefore, it is subject to monitoring by competent authorities. However, this raises questions for all parties concerned: starting with the meaning of food safety culture, the challenge of how to implement it successfully, and finally how to control its application.

The concept of food safety culture is based on ensuring food safety through clearly regulated activities and responsibilities via Hazard Analysis Critical Control Point (HACCP) and supplementary measures. In addition, food safety culture should be anchored in the mind-set of employees through its effective integration into company policy in a way that food safety almost automatically results from the behaviour of each employee. This is essential to effectively reach operational hygiene on all levels.

Furthermore, the application of the HACCP concept for hygienic handling of food and thus the prevention of

Sigune Lopp

Sigune.Lopp@oe.hs-fulda.de

Joel M. Goebelbecker

joel.goebelbecker@adm.com

1 Department of Nutritional, Food and Consumer Sciences, Fulda University of Applied Sciences, Fulda, Germany

2 ADM WILD Europe GmbH \& Co. KG, Heidelberg, Germany food-borne infections in all areas of food production has long been a recognised and accepted procedure. As stipulated by Regulation (EC) 852/2004, the application of this concept should be consistently implemented and monitored at all stages of food processing and storage by now.

However, when looking at recent figures for the main reasons for complaints by the German Federal Office of Consumer Protection and Food Safety (BVL 2019), the question arises how the requirements of the HACCP concept on the one hand and the high number of hygiene violations on the other hand can be matched (Fig. 1).

Combined with data on food-borne outbreaks, recalls or product alerts (EFSA 2018), it has become clear that the mandatory HACCP-based approach to the management of health hazards posed by food either does not work as it stands, or is not implemented successfully. The concept must not only be introduced, but ultimately implemented with the people who must effectively put the system into practice.

This has been recognised by the legislator and in the draft of the Regulation (EC) 852/2004, further aspects of food safety were supplemented. What are the proposed amendments about?

\section{Proposal for Regulation (EC) No 852/2004}

The draft revision of regulation (EC) No 852/2004 on the hygiene of foodstuffs (EC 2020a) proposes three main objectives: 


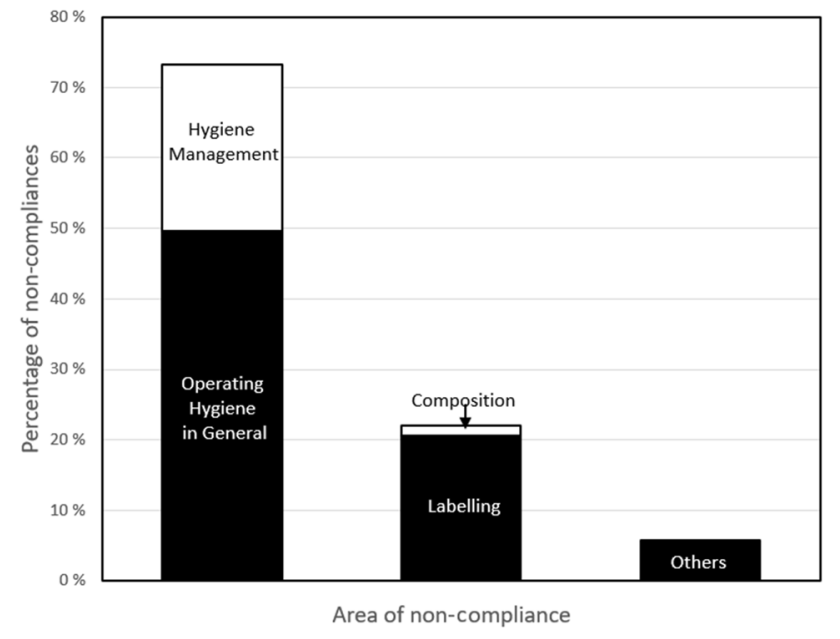

Fig. 1 Non-compliances during operational inspections in Germany in 2018 (based on BVL 2019); 63,820 out of 504.730 controlled companies showed non-compliances during inspection

- Improving food safety by bringing EU standards in line with new international standards (WHO Codex)

- Ensuring appropriate food safety measures for food donations

- Reducing food waste as part of the European Green Deal

This will take a fresh look at various aspects of food safety:

- Handling and labelling of allergens

- Inclusion of a food safety culture in general guidelines

Both aspects appear to be directly manageable through the implementation and application of a well-adapted HACCP approach. On the other hand, the above-mentioned observation shows that the purely formal implementation is not enough, and that extended efforts must be made to anchor the HACCP concept in the minds of all those involved in food production and storage in order to implement it effectively.

This culture of food safety inevitably includes the conscious risk-based handling of allergens and the assurance of appropriate food safety measures for food donations, so that the introduction of a food safety culture for all companies in the food sector can cover all central demands of the proposed revision.

However, useful and imperative the introduction of a verifiable food safety culture may seem, it is not welcomed with the same enthusiasm by all stakeholders:

Examining the feedback on the revision of regulation (EC) No 852/2004 (EC 2020b), it becomes clear that opinions diverge on the introduction of a culture of food safety. The feedback from companies is predominantly critical and negative. In contrast, the scientific community predominantly approves the proposal.

Why are opinions so divergent and are there good reasons for this? Are there ways of turning rejection into approval from a business perspective?

\section{Practical significance of food safety culture}

The culture of food safety is defined in a way that all participants within an organisation on all levels think and act in their daily work to ensure food safety. To achieve the latter, systems and processes need to be linked to people and their behaviours. In this regard, the challenge mostly consists of closing the gap between knowledge and behaviour.

The current draft Regulation is promoting a strong voluntary compliance by the industry. This risk-based approach focuses on the activities, areas or resources of businesses where the risks of non-compliance with food safety are of greatest concern. A key component is to promote understanding of compliance requirements and provide information to assist all participants in the business to comply easily.

For users, one of the challenges now is how to integrate the food safety culture into the operational and decisionmaking structures, and how to measure and ultimately validate it. To this end, the dimensions of food safety culture mentioned in the draft Regulation are described in more detail below.

\subsection{Presence of food safety culture}

The draft Regulation (EC 2020a), as currently proposed, would require the food business operator to establish, maintain and demonstrate an appropriate corporate culture by exemplifying a good practice of food safety by raising awareness of relevant hazards. Additionally, through communication between all employees, including communication of deviations and expectations. First and foremost, the food business operator should provide sufficient resources ensuring safe and hygienic handling of food.

\subsection{Management commitment}

According to the draft Regulation (EC 2020a), the management of a food business is obligated to define the roles and responsibilities and clearly communicate them within the organisation. The leaders must verify that actions are carried out efficiently and that documentation is kept up to date, and ensure proper training of all staff and continuous improvement of the food safety management system. 


\subsection{Adequacy of food safety culture}

The compliance requirements provided are fundamental to the culture of food safety and must be tailored to each and every business's needs. Above all, the knowledge of all dimensions of food safety could prove to be an effective first step towards an implementation as there is not a common approach to assess the performance of the food safety culture throughout the industry yet.

There is still a lack of understanding on how to develop general programmes to incentivise a positive culture, and how to benchmark the level of maturity of food safety according to GFSI (2018).

The legislator's approach, based on the precautionary principle, requires a careful consideration of the established business model and the targeted behaviour. In practical terms, the culture should be designed in a way that makes it analysable and comparable for continuous improvement, and to ensure that it can be documented in the context of an external review.

\section{Concept for evaluating food safety culture}

A first step to fulfil the draft regulation and the requirements of GFSI-recognised standards could be performed by a selfassessment and include an evaluation by empirical data collection. Subsequently, improvements need to be identified to raise the culture of food safety. As mentioned in the GFSI's position paper (GFSI 2018), food safety culture is defined as "[...] shared values, beliefs and norms that affect mind-set and behaviour towards food safety in, across and throughout an organization."

This statement concludes that the corporate culture (and therefore each individual employee) has a substantial influence on food safety and, as a result, on the consumers' health. The approach suggests to move away from a distinct food safety management system based solely on rules and regulations to the introduction of a positive corporate culture.

A positive corporate culture is strongly influenced by the company's leadership and its general trust in employees. Consequently, this must be actively demonstrated by managers to motivate employees to establish a behaviourbased management system and create a modern, risk-based corporate culture and thus contribute to constant food safety (GFSI 2018).

Such a concept could be implemented in four steps:

1. Creation of a fundamental company policy that is available for all employees at any time and regularly updated and communicated. It should include behavioural motivations and incentivize its application.
2. Conduction of a short employee survey and optionally an enriched survey of selected management staff on subjective impressions and objective facts. A survey should include dimensions such as food safety communication, risk awareness and training (GFSI 2018).

3. Determination of the current state by survey data evaluation and identification of improvement opportunities, highlighting deficits in the entire culture or in specific departments (BRC 2019). The results could be illustrated by a traffic light system to clearly indicate the potential areas for improvement.

4. Optimization of the culture through specific actions, such as improving bottom-up communication or implementing an incentive system linked to strategic food safety objectives (GFSI 2018).

\section{Conclusions}

Subsequently, practical recommendations for a successful and progressive cultivation of food safety could be illustrated as:

- The use of the most positive incentives: empowering employees to live a culture that allows them to suggest improvements without fearing disadvantages

- Actively counteracting a "culture of punishment": Possibility of the opposite effect by the formation of groups that pursue their own goals secluded from others.

The latter should be followed by criteria for their successful implementation:

- management support and provision of all necessary resources (GFSI 2018),

- employee motivation (creating incentives),

- role model culture demonstrated by management, and

- ubiquity manifestation throughout the company.

In summary, the implementation of a reliable concept does not require too much effort, nor is the matter itself inconceivable. If designed in an encouraging way for all employees, it will be recognized and lived. Therefore, the importance of a strong food safety culture should not be feared but welcomingly embraced for an early and fruitful harvest of its long-term rewards.

Author contributions All authors contributed to the article conception and design. Material preparation, data collection and analysis were performed by SL, JG and PR. The first draft of the manuscript was written by all authors and all authors commented on previous versions of the manuscript. All authors read and approved the final manuscript. 
Funding Open Access funding enabled and organized by Projekt DEAL.

\section{Compliance with ethical standards}

Conflict of interest The authors declare that they have no conflict of interest.

Open Access This article is licensed under a Creative Commons Attribution 4.0 International License, which permits use, sharing, adaptation, distribution and reproduction in any medium or format, as long as you give appropriate credit to the original author(s) and the source, provide a link to the Creative Commons licence, and indicate if changes were made. The images or other third party material in this article are included in the article's Creative Commons licence, unless indicated otherwise in a credit line to the material. If material is not included in the article's Creative Commons licence and your intended use is not permitted by statutory regulation or exceeds the permitted use, you will need to obtain permission directly from the copyright holder. To view a copy of this licence, visit http://creativecommons.org/licenses/by/4.0/.

\section{References}

BRC Global Standards (2019) BRCGS culture excellence food safety culture module implementation manual. https://www.brcgs.com/ media/1424827/brcgs_culture_excellence_site_ma-nual_issue _10-003.pdf. Accessed 9 Jan 2020
BVL (2019) (German Federal Office of Consumer Protection and Food Safety), Press release from 19.09.2019. https://www. bvl.bund.de/SharedDocs/Pressemitteilungen/01_lebensmitt el/2019/2019_09_19_PI_Lebensmittelueberwachung_2018.html. Accessed 5 Oct 2020

EC (European Commission) (2020a) COMMISSION REGULATION (EU) .../... amending the Annexes to Regulation (EC) No 852/2004 of the European Parliament and of the Council on the hygiene of foodstuffs as regards food allergen management, redistribution of food and food safety culture; Document Ares (2020)3623256; https://eur-lex.europa.eu/legal-content/EN/ ALL/?uri=PI_COM:Ares(2020)3623256. Accessed 12 Nov 2020

EC (European Commission) (2020b) Feedback received on: Food safety, allergies \& food waste - new EU rules; https://ec.europ a.eu/info/law/better-regulation/have-your-say/initiatives/12230 -Hygiene-rules-on-allergens-foodredistribution-and-food-safet y-culture/feedback?p_id=8190753. Accessed 12 Nov 2020

EFSA 2019: RASFF-The Rapid Alert System for Food and Feed2018 annual report; https://ec.europa.eu/food/sites/food/files/safet y/docs/rasff_annual_report_2018.pdf. Accessed 5 Oct 2020

GFSI 2018: Global Food Safety Initiative: A Culture of Food Safety, V1.0 - 4/11/18 (GFSI); https://mygfsi.com/wp-content/uploa ds/2019/09/GFSI-Food-Safety-Culture-Full.pdf. Accessed 5 Oct 2020

Publisher's Note Springer Nature remains neutral with regard to jurisdictional claims in published maps and institutional affiliations. 